\title{
Influencing ethical leadership and job satisfaction through work ethics culture
}

DOI nr: https://doi.org/10.35683/jcm19048.52

\section{J MITONGA-MONGA}

University of Johannesburg, Industrial Psychology and People Management jeremym@uj.ac.za

ORCID NUMBER: http://orcid.org/0000-0002-4287-7498

\section{AP FLOTMAN*}

University of South Africa, Industrial and Organisational Psychology

flotma@unisa.ac.za

ORCID NUMBER: http://orcid.org/0000-0001-5663-7279

* corresponding author

\section{EM MOERANE}

University of South Africa, Human Resource Management

moeraem@unisa.ac.za

ORCID NUMBER: http://orcid.org/0000-0002-6573-8634

\begin{abstract}
There is a growing realisation that organisational resources such as organisational culture and ethical leadership, directly affect employee attitudes and workplace behaviour. This also applies to the Democratic Republic of the Congo (DRC), where political and economic instability have resulted in mismanagement, corruption and unethical leadership practices. The present study investigated the mediating effects of work ethics culture in the relationship between ethical leadership and employees' job satisfaction perceptions, in an attempt to explore the impact of perceived work ethics culture. Ethical leadership was measured by the Ethical Leadership Scale, while job satisfaction was measured by the Job Satisfaction Questionnaire, and work ethics culture by the Corporate Ethical Virtues. The sample comprised of 839 employees from a railway organisation in the DRC. Mediation analysis and partial least squares SEM (PLS-SEM) were used to analyse the data. The results revealed that the work ethics culture emerged as mediator of ethical leadership and employees' job satisfaction relationships. This research provides suggestions for human resources practitioners and leaders when developing strategies to foster and enforce a positive and ethical work environment, which may increase workers' satisfaction and their performance, and decrease their turnover intention.
\end{abstract}


Key phrases

Ethical leadership; Democratic Republic of the Congo (DRC); job satisfaction; partial least squares and work ethics culture

\section{INTRODUCTION}

Ethical leadership refers to the demonstration of normatively suitable behaviour through personal actions and interpersonal relationships, as well as the promotion of such conduct to followers through two-way communication, reinforcement and decision-making (Brown, Trevino \& Harrison 2005:121; Mitonga-Monga \& Cilliers 2016:39). Work ethics culture is perceived to be the ethical quality of an organisation, which is defined as the shared values, norms and beliefs that can encourage ethical behaviour (Huhtala, Kaptein \& Feldt 2016:337; Kaptein 2008:926). Scholars and practitioners are focusing on examining how positive, effective and ethical leadership and work ethics culture can uphold ethical comportment and decrease unethical behaviour or wrong deeds (Huhtala \& Feldt 2016:11; Treviño 2010:127). According to Mitonga-Monga and Cilliers (2016:37), there is a growing awareness that organisational resources such as organisational culture, values and virtues, as well as effective leadership are important factors, which affect employees' positive attitudes and behaviours such as satisfaction, commitment and discretionary behaviour. Gaining a good understanding of these organisational resources for such attitudes and behaviours is now regarded as an important component of research agendas, which relate to business ethics (Brown \& Treviño 2014:589). Recently, studies have been conducted to link these lines of scrutiny, and to explore how leadership ethics and the work ethics culture are associated with a broader range of work-related outcomes in addition to either ethical or unethical practices or comportment (Mayer 2014:417; Mitonga-Monga \& Cilliers 2015:246).

The potential of leaders' ethicality and values, norms and practices in influencing employees' outcomes has been investigated in Western countries (Kalshoven, Den Hartog \& De Hoogh 2011:55; Treviño \& Nelson 2010:88; Huhtala et al. 2016:10). Although initial research on ethical leadership is encouraging and evidenced, there is a dearth of research that explores the underlying mechanism to explain how ethical leadership and work ethics culture impact employees' job satisfaction (Brown \& Treviño 2006a:956) in developing countries such as the DRC. This is a specific and crucial question to examine in a developing economy, where the future of the nation pivots on the integrity and quality of leaders' ethicality and positive, ethical and favourable work environments across public and private business sectors (Mitonga-Monga \& Cilliers 2016:40). This study contributes to the growing theoretical debate 
on and empirical research into ethical leadership and work ethics culture by trying to unravel how employees' positive perceptions of ethical leadership and work ethics culture affect their job satisfaction (Kalshoven, Den Hartog \& De Hoogh 2013:212). This article, therefore, adds to the emerging debate around ethical leadership and work ethics culture by exploring its effects on employees' levels of job satisfaction in a railway organisation in the DRC.

\section{DRC WORK SETTING}

The DRC is an emerging, developing country with huge economic prospective because of its vast mineral and natural wealth such as gold, copper, diamonds, coltan and rich forests (Mitonga-Monga, Flotman \& Cilliers 2016:327). Political and economic instability for the past three decades has resulted in a higher level of inflation, mismanagement, corruption, unethical behaviour and poor, mediocre and autocratic leadership (Mitonga-Monga \& Cilliers 2015:244). This resulted in the country being ranked below $7 \%$ in all seven indicators, with the lowest scores on leadership accountability, government effectiveness, rule of law, political instability and control of corruption (Mitonga-Monga \& Cilliers 2016:38; Transparency International 2018:122). Currently, the country realises the need to speed up their institutional, economic, political and social reform to ensure stability, peace and growth, whilst reducing its high levels of corruption in order to ensure a culture of good governance across both the public and private sectors. In a typical DRC organisation, the above scenario manifests as unethical behaviour and low job satisfaction, which may be addressed through the development of effective, accountable and ethical leaders to shape a positive culture and facilitate employees' general psychological well-being, including job satisfaction.

\section{THEORETICAL PERSPECTIVES}

This article investigates the mediating effects of work ethics culture in the relationship between ethical leadership and employee's job satisfaction. It also suggests how leaders can play a crucial role in the creation of an ethical and favourable working environment, whilst enhancing employees' attitudes and behaviour (Mitonga-Monga 2018:4). Research findings on the above-mentioned variables are well documented (Avey, Wernsing \& Palanski 2012:24, Mitonga-Monga 2018:5; Salem 2015:240; Valentine, Greller \& Richtermeyer 2006:583; Tu, Lu \& Yu 2017:230), but the moderation role of work ethics culture in the relationship between leaders' ethicality and employees' satisfaction is limited. The following section discusses the ethical leadership (EL) model, which Brown and his colleagues (2005:120) developed, and the corporate ethical virtue (CEV) and job satisfaction (JS) model, which Lock (1976:1299) developed. 


\subsection{Ethical leadership}

Ethical leadership is a concept of interest for practitioners and scholars alike (MitongaMonga \& Cilliers 2016:39). Ethical leadership refers to the demonstration of normatively appropriate conduct through personal action and interpersonal relationships, and the promotion of such conduct towards employees through two-way communication, reinforcement and decision-making (Brown et al. 2005:130). Ethical leadership has been labelled as referring to both moral persons and moral managers (Mitonga-Monga \& Cilliers 2016:38). (1) Moral persons - ethical leaders are perceived to be fair, principled and genuine individuals who show concern for their employees. Ethical leaders are viewed as being honest, fair, principled decision makers and upright citizens. Additionally, these leaders demonstrate concern for their followers, and behave in an ethical manner in their professional and personal life. (2) Moral managers - ethical leaders set proper channels of communication in the organisation, and reinforce high ethical standards (Brown et al. 2005:129).

Ethical leaders tend to engender constructive employees' outcomes because they care, act with integrity, treat their followers with respect and dignity, are perceived as being trustworthy, and are fair (Brown et al. 2005:129). Workers who perceive fair treatment from their ethical leaders are more likely to be satisfied workers, perform better and allot their time to the organisation. The ethical leadership concept has received some criticism because it shows a strong conceptual similarity towards other leadership styles such as transformational leadership and authentic leadership (Chughtai, Byrne \& Flood 2015:654). According to Walumbwa, Avolio, Gardner, Wernsing and Peterson (2008:92), these three types of leadership styles are similar, since they are characterised by genuine concern for others, honesty and trustworthiness, where the leaders serve as role models for others, make ethical decisions and refrain from engaging in unethical behaviour or malpractices.

Brown and Treviño (2006b:955) indicate that ethical leaders go beyond these comportments by trying to positively influence their followers' ethical conduct, communicating ethical standards and holding workers accountable for those standards through the use of rewards and punishments. One may conclude that ethical leadership is distinct from these others leadership styles. Previous research indicates that ethical leadership better explained additional variances in some work-related outcomes in comparison to other leadership approaches (Chughtai et al. 2015:654; Kalshoven et al. 2011:53). Prior studies, which Valentine et al. (2006:583) conducted, found that ethical leadership had positive effects on employees' responses and satisfaction levels. Employees who work for ethical leaders are usually satisfied with their work conditions, leader/s and the organisation. In other words, 
employees are more likely to experience job satisfaction and maintain good relations and state at work while working for ethical leaders.

Hypothesis 1: Ethical leadership positively influences employees' job satisfaction in a railway organisation in the $\mathrm{DRC}$.

\subsection{Work ethics culture}

WEC refers to a subset of organisation culture, consisting of a formal (codes of ethics, rewards systems) and informal (peer behaviour, ethical norms) system that can encourage either ethical or unethical behaviour (Treviño \& Nelson 2010:54). Development of the work ethics culture has extended from a single dimensional construct (Treviño, Butterfield \& McCabe 1998:450) to stating its multi-dimensions (Kaptein 2008:926). The Corporate Ethical Virtues (CEV) model (Kaptein 2008:926) is the first empirically validated multi-dimensional model to measure the work ethics culture construct. It distinguishes between eight virtues that support and encourage the work ethics culture of an organisation and, by implication, the ethical comportment of an organisation's members (Mitonga-Monga \& Cilliers 2015:241). This approach is based on the concept of virtue ethics, which originate in the work of Plato and Aristotle. According to Kaptein (2008:261), the virtuousness of an organisation can be determined by the extent to which its corporate culture encourages employees to act ethically, hence preventing them from engaging in unethical behaviour.

The theory is normative, suggesting that both the workers and the organisation should possess some features (virtues) that promote acting according to what is seen to be morally correct, and promote the ethicality of the organisation (Kangas, Feldt, Huhtala \& Rantanen $2014: 163)$. According to literature, the following eight normative virtues can support ethical comportments in the organisation: (1) clarity - refers to the extent to which the organisation provides a clear and comprehensible ethical code of conduct and normative expectations; (2) congruency of supervisor and (3) congruency of management - refer to the extent to which employees perceive their managers as good, ethical role models, and people with integrity; (4) feasibility - refers to the extent to which the organisation offers adequate resources and practical conditions that enable ethical actions; (5) supportability - refers to the extent to which the organisation provides support and trust, and urges workers to commit to common values; (6) transparency - refers to the extent to which the organisation creates visibility of (un)ethical comportment and its consequences; (7) discuss ability - refers to the extent to which the organisation creates a platform or possibility to speak out and discuss ethical matters; and (8) sanction ability - refers to the extent to which the organisation reinforces ethical conduct by rewarding ethical behaviour and punishing unethical ones. All 
these virtues denote the ethical characteristics of an organisation's culture, which boost positive and ethical behaviour among the organisation's members (Kaptein 2008:940).

Previous research indicates that ethical virtues, as an organisational resource, associate positively with employees' work-related outcomes of job satisfaction and commitment (Huhtala, Feldt, Hyvönen \& Muano 2013:266). Given previous findings, which relate to employees' outcomes to organisational ethics and work ethics culture perceptions, we expect work ethics culture to associate positively with employees' levels of job satisfaction (Schwepker 2001:41; Treviño \& Nelson 2010:155).

Hypothesis 2: Work ethics culture relates indirectly and positively to employee job satisfaction in a railway organisation in the DRC.

\subsection{Job satisfaction}

Job satisfaction has been a topic of interest for academics and practitioners for many decades (Mitonga-Monga et al. 2016:327; Tu et al. 2017:229), and has been studied from diverse perspectives. The popularity of this construct can be ascribed to the significance of job satisfaction in respect of the physical and mental well-being of workers (Sehunoe, Viviers \& Mayer 2015:124; Strümpfer \& De Bruin 2009:2). Job satisfaction refers to a pleasurable emotional state, which results from the appraisal of one's job, and an affective reaction and an attitude towards one's job (Mullins 2013:124). Job satisfaction is perceived to be an essential indicator of how employees feel about their job, as well as a predictor of some work-related attitudes and behaviours (Mullins 2013:124). Job satisfaction was found to decrease workers' absenteeism and turnover intention, and to improve work climate, productivity and performance (Abou-Hashish 2017:152; Strand \& Dore 2009:392). Additionally, job satisfaction influences the mobilisation of resources, and is perceived to be a positive organisational behaviour construct (Sehunoe et al. 2015:124). This study approaches job satisfaction from Locke's (1976:1297) perspective, as he describes it as an individual's feeling of a pleasant or positive emotional condition, which is derived from his or her appreciation of the job. Based on the value-percept theory, employees will tend to be satisfied when their job provides the things that they value (Colquitt, Lepine \& Wesson 2014:124).

Values are perceived as those things that individual employees consciously or subconsciously want to seek or attain (Colquit et al. 2014:124). The value-percept theory suggests that workers evaluate job satisfaction according to the specific facet of the job. These facets are as follows: pay satisfaction - refers to workers' feelings about their pay and the organisation's rewards system, including whether it is as much as they deserve, secure, 
and adequate for normal and luxury items. Promotion satisfaction - refers to how employees perceive the organisation's promotion policies and their execution, and whether they think that they are sufficiently frequent and fair. Supervision satisfaction - refers to the extent to which employees perceive their direct manager to be competent, polite and a good communicator. Co-worker satisfaction - refers to the extent to which employees believe that their co-workers are smart, responsible and helpful. Satisfaction with the work - refers to workers' perceptions about whether or not the organisation provides positive working conditions, working hours and clear role and task expectations. These five facets of job satisfaction have been the subject of most empirical research to date as a multifaceted construct (Belias, Koustelios, Vairaktarakis \& Sdrolias 2014:315). Previous studies indicated that job satisfaction relates negatively to turnover intention (Emami, Moradi, Idrus \& Almutairi 2012:21).

\subsection{Relationship between ethical leadership and job satisfaction}

According to both the social exchange theory (Blau 1964:123) and the expectancy theory (Vroom 1964:124), the obligation of a leader in an organisation is to create a fair, positive and ethical working atmosphere, which satisfies the needs and expectations of his/her followers. The equity theory concurs, as it prescribes that leaders should be fair, credible role models and trustworthy, because employees expect to be rewarded for their hard work, and feel that they are treated fairly (Salem 2015:241). A fair relationship between a leader and his/her followers is crucial for the success of any organisation (Yang 2014:515). Leaders who act with integrity, show concern for others, treat them with respect and dignity, and support and strengthen the fair social exchange relationship, may influence workers' job satisfaction in a positive manner (Valentine et al. 2006:584). Employees under the control of a fair and ethical leader understand what they should and should not do. They have a clear view of the appropriateness and inappropriateness of their conduct, which, in turn, helps to nurture individual job satisfaction (Mitonga-Monga \& Cilliers 2016:40).

Being exposed to a role model leader who displays respect and dignity, and acts with integrity and fairness creates the possibility that the employees will most likely be happy with the organisation's reward system, promotion opportunities, relationships with colleagues and working conditions (Tu et al. 2017:240). Previous studies revealed that ethical leadership has a positive influence on employees' job satisfaction (Avey et al. 2012:30, Valentine et al. 2006:582). Hence, we propose that ethical leadership predicts employees' job satisfaction. Several studies have shed light on the effects that work ethics culture can have on an organisation (Huhtala et al. 2013:280). A higher level of organisational ethics was found to 
relate positively with certain individual outcomes such as job satisfaction and commitment (Brown \& Mitchell 2010:610; Schwepker 2001:50).

Work ethics culture is considered to be a resource that can energize both leaders and followers by supporting ethics and virtuous comportments, which, in turn, may enhance a variety of work-related outcomes. This implies that organisations that emphasise ethical virtues and provide clear norms and expectations regarding ethical behaviour, will increase employees' levels of satisfaction with their work conditions and relationships with colleagues. The work ethics culture has been found to relate to employees' well-being and commitment (Huhtala \& Feldt 2016:12). It can, therefore, be presumed that the work ethics culture also denotes a favourable, positive and ethical environment for workers regarding job satisfaction. Previous research showed that organisational ethics influence employees' levels of commitment, job satisfaction and lower levels of turnover intentions (Ambrose, Arnauld \& Schminke 2008:330), although prior studies provide empirical support for the notion that organisational ethics relate positively to work-related outcomes such as commitment and job satisfaction (Mitonga-Monga \& Cilliers 2016:39). Evidence of leaders' ethicality and organisational culture ethics effecting job satisfaction is scarce and unclear in the work settings of a developing country such as the DRC.

\section{GOAL OF THE STUDY}

The study determines the extent to which the perceived work ethics culture influences ethical leadership and employees' job satisfaction at a railway organisation in the DRC. The question that guided the investigation is as follows: To what extent do perceptions of the work ethics culture amongst railway workers in the DRC affect their self-reported ethical leadership and job satisfaction? This study will add value to the ethical behaviour, virtuous literature and design of human resource interventions to enhance employees' positive perceptions of their leaders, job satisfaction and well-being. Employees could in future also inform management to be aware of and to consolidate efforts to encourage ethical virtues and leadership practices in a developing country like the DRC, and urge them to rule by example, respect and dignity, and to create a positive ethical working environment. This could possibly upsurge individual and organisational productivity in the economic setting of an emerging developing country. 


\section{METHOD}

\subsection{Participants and setting}

The sample consisted of a non-probability purposive sample of 839 employees at a railway organisation in the DRC. Only permanently employed employees were considered and included for inclusion in the sample. Participants were briefed in a covering letter sent with the surveys about the goals of the study and how to complete the questionnaires. The letter and instruments were printed in a booklet and distributed to the population. The final sample was represented by $68 \%$ males and $32 \%$ females. The respondents were mostly married (47\%), with a university education degree (38\%), in their early to middle adulthood (26 to 40 years), and a minority had six to ten years of experience in the organisation (31\%). The participating organisation is a public entity and comprises of $(n=13019)$ employees. The organisation provides services such as transport for the population, goods, copper and other minerals.

\subsection{Measuring instruments}

The work ethics culture was measured by using the Corporate Ethical Virtue Questionnaire (CEVQ: Kaptein 2008). The CEVQ is a self-reported measure, which comprises 58 items on a five-point Likert scale ( $1=$ strongly disagree, $5=$ strongly agree). The example of the scale includes: "The organisation makes it sufficiently clear to me how I should deal with confidential information"; "My supervisor sets a good example in terms of ethical behaviour"; "The conduct of senior management reflects a shared set of norms and values"; "I have adequate resources at my disposal to carry out tasks"; "In my immediate working environment a mutual relationship of trust prevails between employees and management"; "If a colleague does something, which is not permitted, my manager will find out about it"; "In my immediate working environment there is adequate opportunity to discuss unethical conduct"; and "In my immediate working environment ethical conduct is rewarded". Kaptein (2008) reports internal consistency Cronbach alpha coefficients, which range from 0.93 and 0.96 for the CEVQ. A Cronbach alpha coefficient (internal consistency) of 0.79 to 0.97 was obtained for this study.

Employees' perceptions of their leaders' ethical behaviour was measured by using the Ethical Leadership Scale (ELS) (Brown et al. 2005). The scale is a self-reported measure, comprising of ten items scored on a five-point Likert scale $(1=$ strongly disagree, $5=$ strongly agree). The example of items includes: "Set an example of how to do things the right way in terms of ethics"; and "The supervisor disciplines co-workers who violate ethical standards and conduct”. Brown et al. (2005) report an internal consistency Cronbach alpha 
coefficient of 0.87 for the ELS. In this study, a Cronbach alpha index of 0.90 was obtained for the scale.

Employees' job satisfaction was measured by using the Job Satisfaction Questionnaire (JSQ: Vitell \& Davis 1990). The JSQ is a 20-item self-report measure, which uses a fivepoint Likert scale ( $1=$ strongly disagree, $5=$ strongly agree). Examples of items from the measure include: "My organisation pays better than competitors"; "My supervisor doesn't listen to me"; "I enjoy working with the people here"; "Promotions are infrequent in my organisation"; and "I would rather be doing another job". Vitell and Davis (1990) report internal consistency Cronbach alpha coefficients, which ranged from 0.76 and 0.89 for the JSQ. A Cronbach alpha coefficient, which ranged from 0.72 to 0.92 was obtained in this study.

\subsection{Research procedure}

The research was cleared by both the Ethics Research Committee of the University of South Africa, and the management of the organisation involved in the study. A package was distributed to the participants by the first author consisting of the following: a consent form, a letter indicating the purpose of the study, which was attached to the questionnaire, and a questionnaire that was distributed in hardcopy format. The cover letter stipulated that participation in the research was voluntary and that all respondents would remain anonymous, and that the information obtained would be used for research purposes only. Upon completion of the questionnaires, each participant was requested (as stipulated in the instructions by the first author) to sign the consent form and include it with the completed instruments in the envelope for return to the researcher. It took approximately 35 minutes to complete the questionnaire. Permission to use the questionnaires was obtained from the respective authors (owners of the instruments).

\subsection{Statistical analysis}

The data was analysed by using the Statistical Package for Social Sciences (SPSS), version 25, for descriptive analysis, the structural equation model (SEM), and the Smart Partial Least Squares SEM (PLS-SEM), version 2.0 (Hair, Hult, Ringle \& Sarstedt 2014:123; Wong $2011: 52)$. The first step involved determining the mean standard deviations, whilst assessing the measurement model for reliability and validity (Hair et al. 2014:124; Jöreskog \& Wold 1982:269). A cut-off of 0.70 was used to load the indicators. Loadings above 0.70 indicated that the construct explained over $50 \%$ of the indicator's variance. Once the construct measures were confirmed as reliable and valid, the second step assessed the structural model results (Hair et al. 2014:124) to determine whether the structural relationships 
between the work ethics culture, ethical leadership and job satisfaction were significant, meaningful, and tested the hypotheses. Prior to interpreting the path coefficients, collinearity was examined between ethical leadership and work ethics culture constructs, as these served as predictors of relationship value. As a rule of thumb, variance inflation factor values of $(\mathrm{VIF} \leq 5)$ were observed as non-indicative of collinearity. Blindfolding was used to evaluate the model's predictive relevance or accuracy for each of the endogenous constructs. Cut-off of $R^{2}$ values, which ranged between $0.25 \leq 0.50 \geq 70$, was used (Hair et al. 2011:124; Henseler, Hubona \& Ray 2016:18). Lastly, the strength and significance of the path coefficients were evaluated for the relationships (structural paths) that were hypothesised between the constructs (Hair et al. 2014:124).

\section{RESULTS}

\subsection{Descriptive statistics, Cronbach alpha, composite reliability, convergent validity and average variance extracted}

The mean, standard deviations, Cronbach's alpha convergent validity and average variance, which were extracted for all the study variables, are presented in Table 1 below. In terms of the CEVS (work ethics culture) variables, sanctionability obtained the highest mean score (M $=4.10 ; \mathrm{SD}=0.63)$, followed by discussability $(\mathrm{M}=4.07 ; \mathrm{SD}=0.60)$, congruency of supervisor $(\mathrm{M}=4.05$; $\mathrm{SD}=.64)$, supportability $(\mathrm{M}=4.05$; $\mathrm{SD}=0.67)$, transparency $(\mathrm{M}=$ $4.02 ; \mathrm{SD}=.69)$ and congruency of management $(\mathrm{M}=4.01 ; \mathrm{SD}=.68)$. The lowest mean score was amongst the clarity variables $(M=3.63$; $S D=.57)$. In terms of the OCS (ethical leadership) variables, the sample that scored highest was concern for sustainability $(\mathrm{M}=$ 4.13; $S D=0.59)$, followed by ethical guidance $(M=4.09 ; S D=.54)$ and power sharing $(M=$ 4.09; SD = .55). The lowest mean score was amongst the people orientation $(M=4.04 ; S D$ $=.55)$, followed by role clarity $(\mathrm{M}=; \mathrm{SD}=)$, integrity $(\mathrm{M}=; \mathrm{SD}=)$ and fairness $(\mathrm{M}=; \mathrm{SD}=)$ variables. In terms of the JS (the JSQ) variables, satisfaction with co-workers obtained the highest mean score $(M=4.15 ; S D=0.55)$, followed by satisfaction with work itself $(M=$ 4.02; $S D=0.67)$, satisfaction with promotion $(M=4.01 ; S D=0.61)$, and satisfaction with supervisor $(\mathrm{M}=4.00 ; \mathrm{SD}=0.74)$. The lowest mean score was satisfaction with pay $(\mathrm{M}=$ 3.95; SD = 0.73). In this sample, all five components implied a relatively high level of job satisfaction. 
Table 1: Measurement model: descriptive statistics, Cronbach alpha coefficient, composite reliability (CR), convergent validity (AVE) and factor loadings

\begin{tabular}{|c|c|c|c|c|c|c|c|c|}
\hline \multirow{2}{*}{\multicolumn{2}{|c|}{ Construct/dimension }} & \multicolumn{2}{|c|}{$\begin{array}{l}\text { Descriptive } \\
\text { statistics }\end{array}$} & \multirow[t]{2}{*}{$R^{2}$ value } & \multirow[t]{2}{*}{$\alpha$ value } & \multirow[t]{2}{*}{$\begin{array}{l}\text { CR } \\
\text { value }\end{array}$} & \multirow[t]{2}{*}{$\begin{array}{l}\text { AVE } \\
\text { value }\end{array}$} & \multirow[t]{2}{*}{$\begin{array}{l}\text { Factor } \\
\text { loading }\end{array}$} \\
\hline & & M & SD & & & & & \\
\hline \multirow{7}{*}{$\begin{array}{l}\text { Work ethics } \\
\text { culture }\end{array}$} & CLA & 3.63 & 0.57 & \multirow[t]{7}{*}{0.633} & \multirow[t]{7}{*}{0.895} & \multirow[t]{7}{*}{0.918} & \multirow[t]{7}{*}{0.615} & 0.859 \\
\hline & CON-M & 4.01 & 0.68 & & & & & 0.793 \\
\hline & CON-S & 4.05 & 0.64 & & & & & 0.892 \\
\hline & DISC & 4.07 & 0.60 & & & & & 0.853 \\
\hline & SANC & 4.10 & 0.63 & & & & & 0.786 \\
\hline & SUP & 4.05 & 0.67 & & & & & 0.837 \\
\hline & TRAN & 4.02 & 0.69 & & & & & 0.882 \\
\hline \multirow{7}{*}{$\begin{array}{l}\text { Ethical } \\
\text { leadership }\end{array}$} & CON-SU & 4.04 & 0.56 & \multirow[t]{7}{*}{0.000} & \multirow[t]{7}{*}{0932} & \multirow[t]{7}{*}{0.943} & \multirow[t]{7}{*}{0.712} & 0.772 \\
\hline & ETH-GUI & 4.02 & 0.61 & & & & & 0.862 \\
\hline & FAI & 3.92 & 0.64 & & & & & 0.747 \\
\hline & INTER & 3.93 & 0.86 & & & & & 0.726 \\
\hline & PEO-OR & 3.99 & 0.63 & & & & & 0.741 \\
\hline & POW-SH & 4.00 & 0.63 & & & & & 0.865 \\
\hline & $\begin{array}{l}\text { ROL- } \\
\text { CLA }\end{array}$ & 3.95 & 0.70 & & & & & 0.764 \\
\hline \multirow[t]{5}{*}{$\begin{array}{l}\text { Job } \\
\text { satisfaction }\end{array}$} & $\begin{array}{l}\text { SAT- } \\
\text { COW }\end{array}$ & 4.15 & 0.55 & \multirow[t]{5}{*}{0.664} & \multirow[t]{5}{*}{0.846} & \multirow[t]{5}{*}{0.890} & \multirow[t]{5}{*}{0.619} & 0.702 \\
\hline & SAT-PA & 3.95 & 0.73 & & & & & 0.804 \\
\hline & SAT-PR & 4.01 & 0.61 & & & & & 0.769 \\
\hline & $\begin{array}{l}\text { SAT- } \\
\text { SUP }\end{array}$ & 4.00 & 0.74 & & & & & 0.829 \\
\hline & SAT-WIT & 4.02 & 0.67 & & & & & 0.824 \\
\hline
\end{tabular}

Notes: $\mathrm{N}=839, \mathrm{M}=$ mean, $\mathrm{SD}=$ standard deviations, $\mathrm{CR}=$ composite reliability, $\mathrm{AVE}=$ average variance extracted, a Value = Cronbach alpha value, $\mathrm{R}^{2}$ values; $\mathrm{CLA}=$ clarity, $\mathrm{CON}-\mathrm{M}=$ congruency of management, CON-Su = congruency of supervisor, DISC = discussability, SAN = sanctionability, SUP = supportability, TRAN = transparency; CON-SU = concern for sustainability, ETH-GUI = ethical guidance, FAI = fairness, INTER = integrity, $\mathrm{PEO}-\mathrm{OR}=$ people orientation, $\mathrm{POW}-\mathrm{SH}=$ power sharing, ROL-CLA = role clarification, SAT-COW = satisfaction with co-worker, SAT-PA = satisfaction with pay, SAT-PR = satisfaction with promotion, SAT-SUP = satisfaction with supervisor, SAT-WIT = satisfaction with the work itself.

Source: Own data

As shown in Table 1, step 1, reflective measurement models were assessed for reliability and validity. In the course of indicator reliability assessment, the feasibility work ethic culture indicator was removed from the initial model because it exhibited a loading below 0.70 and 
would, therefore, have an adverse impact on the construct measure's convergent validity and internal consistency reliability coefficient. All other indicators were retained, as they had loadings of above 0.70 . Table 1 provides evidence of the final set of items that were used. The AVE values for this model exceeded 0.50 for the reflective constructs (Hair et al. 2014:125), thus indicating convergent validity for all constructs. Composite reliability for the three constructs ranged from 0.890 to 0.92 , exceeding the minimum requirement of 0.70 (Tabachnick \& Fidell 2013:189). The Fornell and Larcker (1981:41) criterion demonstrated that all AVE values for the reflective constructs were slightly lower than the squared interconstruct correlations, indicating partial discriminant validity. Similarly, all the indicator loadings were higher than their respective cross-loadings, which provided further evidence of discriminant validity. Once the construct was confirmed as reliable and valid, the next step was to assess the structural equation model results see Figure 1.

\section{Figure 1: Path model and PLS-SEM estimate}

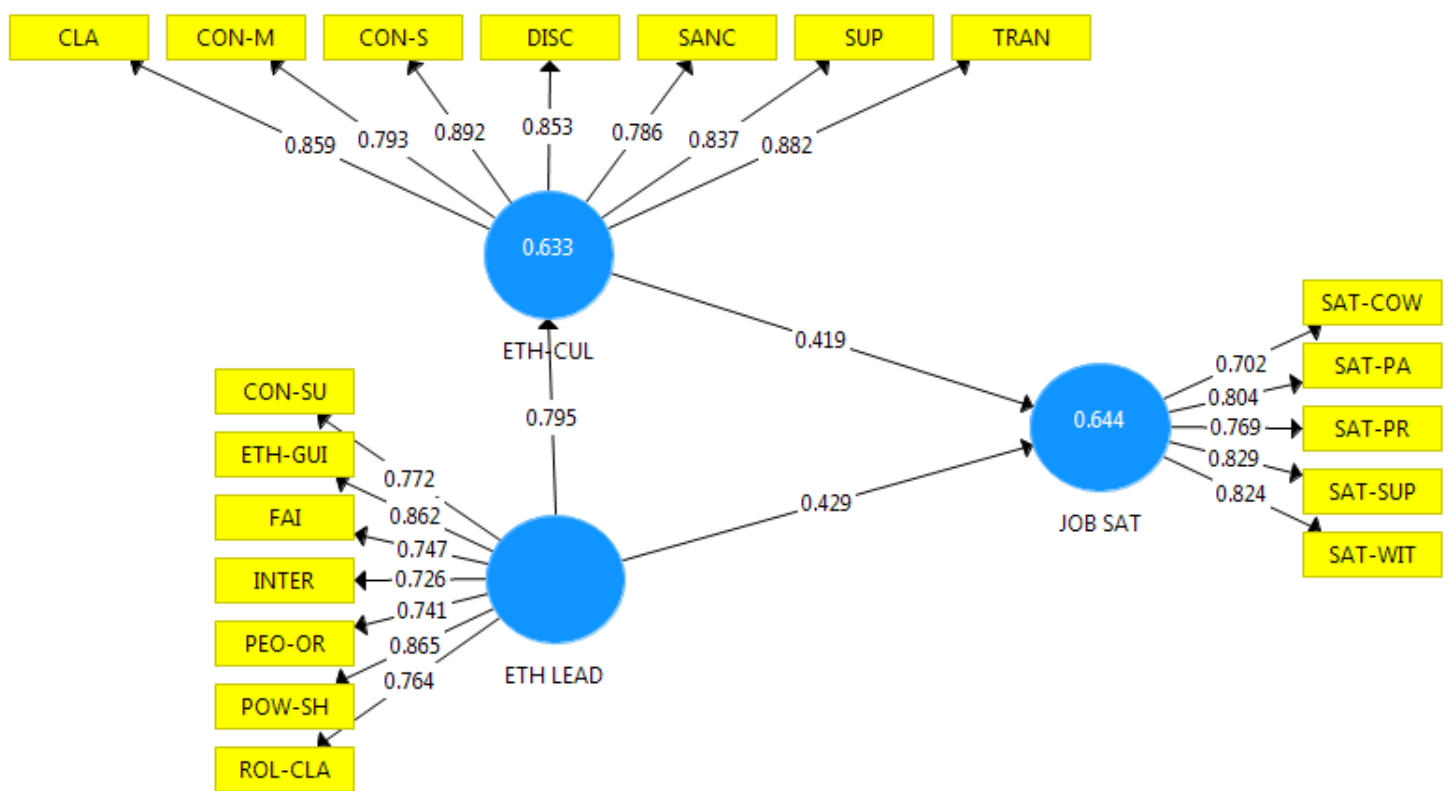

Notes: ${ }^{* * *} p \leq 0.05 ;{ }^{*} p \leq 0.10$; CLA = clarity, CON-M = congruency of management, CON-Su = congruency of supervisor, DISC = discussability, San = sanctionability, SUP = supportability, TRAN = transparency; CON-SU = concern for sustainability, ETH-GUI = ethical guidance, FAI = fairness, INTER = integrity, PEO-OR = people orientation, POW-SH = power sharing, ROL-CLA = role clarification; SAT-COW = satisfaction with co-worker, SAT-PA = satisfaction with pay, SAT-PR = satisfaction with promotion, SAT-SUP = satisfaction with supervisor, SAT-WIT = satisfaction with work itself

Source: Own data

Prior to inferring the path coefficients, the authors explored the structural model for collinearity, which is pertinent because estimation of the path coefficients is based on 
ordinary least squares regressions (Hair et al. 2014:134). The first stage was to examine the collinearity between the work ethics culture and ethical leadership constructs, as these serve as exogenous constructs in the prediction of job satisfaction. VIF values of this analysis were 1.000 , providing confidence that the structural model results were not negatively affected by the collinearity.

Examination of the endogenous construct's predictive power (Figure 1) indictates that relationship values, the primary outcome measure of the model, has a substantial $R^{2}$ value of 0.664. The prediction work ethics culture is higher, with an $R^{2}$ value of 0.633 and, considering the rule of thumb (Hair et al. 2014), this construct's $R^{2}$ values are satisfactory. Blindfolding was also used to evaluate the model's predictive accuracy for each of the endogenous constructs. Running the blindfolding procedure with an omission distance of seven yielded cross-validation redundancy values for both endogenous constructs well above zero (job satisfaction: 0.374; work ethics culture: 0.420 ), providing support for the model's predictive accuracy or relevance.

The final step, namely significance and relevance of the structural model relationships, was assessed. The results from the Boostertraping procedure (125 cases, 5000 samples, no sign changes option) indicate that all three structural relationships are significant $(p \leq 0.05)$. The results in Figure 1 highlight the important role of ethical leadership and the work ethics culture in influencing job satisfaction, with path coefficients of 0.795 and 0.429 , respectively. In addition, the work ethics culture has a significant effect on job satisfaction and shows a path coefficient of 0.419. A different picture emerges when considering the indirect effect of ethical leadership on job satisfaction via the mediator work ethics culture. The corresponding total effect is given by the following equation:

Total effect $=$ direct effect + indirect effect

$=0.333+0.795+0762=0.606$

As shown above, the total effect is much stronger than the direct effect of 0.429 , emphasising the importance of ethical leadership. In addition, these results evidenced that work ethics culture mediates the relationship between ethical leadership and job satisfaction. Table 2 below provides an overview of all total effects and their significance. 
Table 2: $\quad$ Total effects

\begin{tabular}{|l|l|}
\hline Relationship & Total effect \\
\hline Ethical leadership $\longrightarrow$ Job satisfaction & $0.429^{\star \star *}$ \\
\hline Ethical leadership $\longrightarrow$ Work ethics culture & $0.795^{* \star *}$ \\
\hline Work ethics culture $\longrightarrow$ Job satisfaction & $0.419^{* \star \star}$ \\
\hline${ }^{* \star *} \mathrm{p}<0.01$ & \\
\hline
\end{tabular}

Source: Own data

\subsection{Mediating analysis}

The results from analysis of the total effects suggest that the work ethics culture mediates the relationshiship between ethical leadership and job satisfaction, and it is important to test for this prospective mediating effect. Hence, the analysis drew on Hair et al. (2014:135) by answering the following questions: (1) Is the direct effect between ethical leadership and job satisfaction significant when the mediator variable is excluded from the path model? (2) Is the indirect effect via the mediator variable significant after job satisfaction is excluded in the path model? (3) How much of the direct effects does the indirect effect via the mediator absorb?

To answer the first question, the authors excluded the work ethics culture from the path model and ran the Boostertraping procedures with the previously described specifications. As a result, the direct effect between ethical leadership and job satisfaction was 0.765 and significant at $p \leq 0.01$. Providing the answer to the second question requires re-estimating the indirect effect's significance. The corresponding Boostertraping results show that the indirect effect of 0.333 was significant at $p \leq 0.01$. Lastly, the authors computed the variance accounted for (VAF). The VAF = indirect effect/total effect. The results of this last analysis step yielded a VAF value of 0.435 , which, according to Hair et al. (2014:134), suggests that the work ethics culture partially mediates the relationship between ethical leaderhip and job satisfaction.

\section{DISCUSSION}

This research article used the social exchange theory and the social expectancy theory to provide a theoretical grounding for the conceptual framework that sought to expound the effects of work ethics culture in the relationship between ethical leadership and employees' job satisfaction for a railway organisation in the DRC. More specifically, this study postulates that the work ethics culture mediates the relationship between ethical leadership and employees' job satisfaction so that when employees perceived high work ethics culture, their self-reported ethical leadership and job satisfaction were also high. These findings are 
consistent with those of previous research by Mitonga-Monga and Cilliers (2016:40), who found that ethical leaders who shape a positive and favourable ethical workplace, and who provide workers with available resources in the form of ethical behaviour and supportive organisational culture, would likely encourage a high level of performance and well-being. The finding is likely to be explained by the fact that when workers perceive their work environment to be favourable and ethical, they would probably perceive their ethical leaders as social cues for ethical behaviour, and as leaders who help those to develop shared ethical beliefs regarding the job, whilst also providing ethical guidance (Brown \& Mitchell 2010:611).

The results suggest that the work ethics culture influences employees' job satisfaction. This implies that employees who perceive their work environment to support ethical decisionmaking have clear ethical standards, and create shared commitment towards ethical behaviour through fair treatment. Ethical decision-making allows employees to openly discuss unethical behaviour, while the employees believe that ethical behaviour should be rewarded and unethical behaviour punished. They would likely perceive their ethical leader as valuing integrity, and as being caring, honest and fair. This, in turn, could help them to be happy and satisfied with their work conditions and their competent supervisor, to value positive relationships with co-workers, and to engage in productive behaviour (Huhtala et al. 2016:349). These findings are consistent with those of Belias et al. (2015:320), who found that organisational culture relates to employees' job satisfaction.

\subsection{Work ethics culture mediator}

The results suggest that the work ethics culture mediates the relationship between ethical leadership and job satisfaction (Tsai 2011:8). This might be explained by the fact that when employees perceive a positive work ethics culture and high ethical leadership qualities such as honesty, integrity, respect and trustworthiness, they might demonstrate a higher level of job satisfaction, including achieving desired organisational effectiveness. For instance, previous research findings by Mustafa, Ilyas and Rehman (2016:126) suggest that employees, who perceived positive ethics, higher organisational integration, management style, compensation and training; and development features of organisational culture, were likely to demonstrate a relatively high level of job satisfaction. Workers who perceived their workplace to have a strong work ethics culture and deeply embedded ethical virtues, whilst providing positive resources such as support for ethical decisions and actions, clear norms and expectations, and adequate practical conditions (such as time and personal authority), and who perceive their leader as a role model, and a credible, principled ethical decisionmaker, would more likely be satisfied and engage in productive behaviour (Tsai 2011:8). 


\subsection{Implication for human resource management practice}

High-performing organisations attract workers by fostering and creating an ethical working environment, where leaders act with integrity, respect and honesty, and treat others cautiously and with dignity and fairness. Employees also tend to search for and prefer to work for organisations that have a good reputation, whilst promoting ethical conduct under an accountable or ethical leadership (Brown \& Mitchell 2010:614; Mitonga-Monga \& Cilliers 2016:37). Organisations should continuously be encouraged to permanently have clear and well-defined normative codes of conduct, provide practical guidelines on how to create an ethical working environment where ethical leaders are good examples of ethical behaviour by being honest, reliable and upholding the organisation's ethical standards. These ethical attributes are important to improve employees' overall satisfaction, performance and wellbeing. By cultivating proper and practical conditions that encourage ethical behaviour, organisations can prevent employees from being involved in unethical behaviour that might impede their performance and well-being.

The results suggest a need for human resource management to embed the ethical dimension in their goal setting and business strategies, as well as in training programmes for employees and managers and their performance appraisal and rewards systems (Huhtala, Tolvanen \& Muano 2015:411). The results propose that promoting ethical virtues, leaders and co-worker fairness might promote ethical conduct that could be valuable to organisations, as this will enhance employees' job satisfaction, performance, loyalty and discretionary behaviour. Thus, there is a need for organisations to invest more in training programmes that enhance ethical conduct as a way to facilitate honesty, fairness and integrity in organisations. The findings suggest that organisations should invest additional resources in cultivating ethical leaders and ethical virtues, whilst finding innovative ways to enforce and teach ethical conduct to enable workplace ethical decision-making and fairness. Such investments will likely result in employees' positive attitudes such as job satisfaction and performance.

The aforementioned findings lead to practical implications, because it shows that if an organisation has a positive work ethics culture, and if the employees feel that the strength of the work ethics culture has influenced their perceptions of ethical leaders, this will increase their job satisfaction and performance levels. Organisations that need to motivate their staff towards a high level of performance should strive towards a strong work ethics culture, where the leaders act with integrity and fairness. These positive perceptions of ethics can lead employees to higher levels of job satisfaction and performance, and improve their overall well-being. 
This study will add value to ethical behaviour, virtuous literature and the design of human resource interventions to enhance employees' positive perceptions of their leaders, job satisfaction and well-being. Organisational management should be aware of and consolidate efforts to encourage ethical behaviour and practices in a developing country such as the DRC and urge leaders to rule by example, with respect and dignity, whilst creating a positive ethical working environment. This could possibly upsurge individual and organisational productivity in the economic setting of an emerging developing country.

\subsection{Limitations of the study and future research}

There are of course several limitations that should be considered when drawing conclusions from this study. Firstly, the participants represented employees from only one organisation, thus limiting the extent to which the results can be generalised to other occupational work settings. Secondly, the data was based on self-reports, which may imply that the employees' level of satisfaction may affect their perceptions and evaluation of their leaders' ethical behaviour and the quality of the work ethics culture (the magnitude of the effects can be affected by bias owing to common method variance or consistent answers to the questionnaire). As a cross-sectional study design was used, the authors cannot infer causality based on the results. Thirdly, the reliability or feasibility construct of the work ethics culture was below the cut-off of 0.70 (Tabachnick \& Fidell 2013:137), and it was excluded from the tested model. To conclude, the results revealed concurrent influences of work ethics culture in the ethical leadership and employees' job satisfaction outcomes. This provides further support to previous findings about the importance of ethical behaviour practices to enhance employees' levels of job satisfaction and performance in the workplace. Nevertheless, future research could shed more light on the effects of work ethics culture by using samples from various organisations. Future studies could make use of longitudinal organisational samples to obtain more information about how employees from diverse organisations evaluate the strength and change in work ethics culture and ethical leadership. Future studies should shed light on the effects of the work ethics culture, values and different outcomes such as organisational citizenship behaviour, work engagement and organisational identification.

\section{CONCLUSION}

This article explored the mediating effects of the work ethics culture in the relationship between ethical leadership and employees' job satisfaction at a railway organisation in the DRC. Driven by a dearth of research and empirical evidence of the possible influence of the work ethics culture on the relationship between ethical leadership and job satisfaction in a 
developing country setting, this study makes an important contribution to the field of organisational ethics, human resource management, and industrial and organisational psychology. Work ethics culture does have a positive influence on the perceptions of employees concerning their ethical leaders (honest, fair, trustworthy and a person of integrity) and levels of satisfaction. Furthermore, employees tend to be satisfied and productive when they perceive their working environment to be characterised by a positive code of conduct, higher levels of fairness, respect, dignity and trustworthiness from coworkers. Organisations that promote ethical behaviour, fair treatment and respect cultivate a positive environment, which is conducive to staff thriving and becoming excellent and permanent contributors to the long-term competitive success of their organisation.

\section{REFERENCES}

ABOU-HASHISH EA. 2017. Relationship between ethical work climate and nurses' perception of organizational support, commitment, job satisfaction and turnover intent. Nursing Ethics 24(2):151-166. (DOl:http://dx.doi.org/10.1177/0969733015594667).

AMBROSE M, ARNAUD A \& SCHMINKE M. 2008. Individual moral development and ethical climate: The influence of person-organization fit on job attitudes. Journal of Business Ethics 77:323-333.

AVEY JB, WERNSING TS \& PALANSKI ME. 2012. Exploring the process of ethical leadership: The mediating role of employee voice and psychological ownership. Journal of Business Ethics 107(1):21-34. (DOl:https://psycnet.apa.org/doi/10.1007/s10551-012-1298-2.)

BELIAS D, KOUSTELIOS A, VAIRAKTARAKIS G \& SDROLIAS L. 2014. Organisational culture and job satisfaction of Greek Banking Institutions. Social and Behaviour Sciences 175:314-323. (DOl:https://doi.org/10.1016/j.sbspro.2015.01.1206.)

BLAU PM. 1964. Exchange and power in social life. New York: John Wiley.

BROWN ME \& MITCHELL MS. 2010. Ethical and unethical leadership: Exploring new avenues for future research. Business Ethics Quarterly 20:583-616. (DOI:https://doi.org/10.5840/beq201020439.)

BROWN ME \& TREVIÑO LK. 2006a. Ethical leadership: A review and future directions. The Leadership Quarterly 17(6):595-616. (DOl: http://dx.doi.org/10.1016/j.leaqua.2006.10.004.)

BROWN ME \& TREVIÑO LK. 2006b. Socialized charismatic leadership, values congruence, and deviance in work groups. Journal of Applied Psychology 91(4):954-962. (DOl:https://psycnet.apa.org/doi/10.1037/00219010.91.4.954.)

BROWN ME \& TREVIÑO LK. 2014. Do role models matter? An investigation of role modelling as an antecedent of perceived ethical leadership. Journal of Business Ethics 122(4):587-598. (DOl:https://psycnet.apa.org/doi/10.1007/s10551-013-1769-0.)

BROWN ME, TREVINO LK \& HARRISON DA. 2005. Ethical leadership: A social learning perspective for construct development and testing. Organisational Behaviour \& Human Decision Processes 97(2):117-134. (DOI:https://psycnet.apa.org/doi/10.1016/j.obhdp.2005.03.002.)

COLQUITT J, LEPINE J \& WESSON M. 2014. Organisational behaviour: improving performance and commitment in the workplace. London: McGraw-Hill Education. 
CHUGHTAI M, BYRNE M \& FLOOD B. 2015. Linking ethical leadership to employee well-being: the role of trust in supervisor. Journal of Business Ethics 128(3):653-663. (DOl:https://psycnet.apa.org/doi/10.1007/s10551-0142126-7.)

EMAMI R, MORADI E, IDRUS D \& ALMUTAIRI DO. 2012. Investigating the relationship between organizational learning culture, job satisfaction and turnover intention in it SMEs. International Journal of Innovative Ideas 12(1):8-23.

FORNELL C \& LARCKER DF. 1981. Evaluating structural equation models with unobservable variables and measurement error. Journal of Marketing Research 18(1):39-50. (DOI:10.2307/3151312.)

HAIR JF, HULT, GTM, RINGLE CM \& SARSTEDT M. 2014. A primer on partial least squares structural equation modelling. Sage: Thousand Oaks, CA.

HENSELER J, HUBONA G \& RAY AP. 2016. Using PLS path modeling in new technology research: updated guidelines. Industrial Management \& Data Systems 116(1):2-20. (DOl:https://doi.org/10.1108/IMDS-09-20150382.)

HUHTALA M \& FELDT T. 2016. The path from ethical organisational culture to employee commitment: mediating roles of value congruence and work engagement. Scandinavian Journal of Work and Organizational Psychology 1(1):1-14. (DOl:http://dx.doi.org/10.16993/sjwop.6.)

HUHTALA M, TOLVANEN A \& MUANO S. 2015. The associations between ethical organisational culture, burnout and engagement: a multi-level study. Journal of Business and Psychology 32(2):399-414. (DOI:http://dx.doi.org/10.1007/s10869-014-9369-2.)

HUHTALA M, FELDT T, HYVÖNEN K \& MUANO S. 2013. Ethical organisational culture as a context for manager's personal work goals. Journal of Business Ethics 114:265-282.

HUHTALA M, KAPTEIN M \& FELDT T. 2016. How perceived changes in the ethical culture of organizations influence the well-being of managers: a two-year longitudinal study. European Journal of Work and Organizational Psychology 25(3):335-352. (DOI: https://doi.org/10.1080/1359432X.2015.1068761.)

JÖRESKOG KG \& WOLD H. 1982. The ML and PLS techniques for modeling with latent variables: Historical and comparative aspects. In Joreskog KG \& Wold H. Eds. Systems under indirect observation: Causality, structure, prediction. Part I. Amsterdam: North-Holland. (pp 263-270.)

KALSHOVEN K, DEN HARTOG DN \& DE HOOGH AH. 2011. Ethical leadership at work questionnaire (ELW): Development and validation of a multidimensional measure. The Leadership Quarterly 22(1):51-69. (DOl:http://dx.doi.org/10.1016/j.leaqua.2010.12.007.)

KALSHOVEN K, DEN HARTOG DN \& DE HOOGH AH. 2013. Ethical leadership and follower helping and courtesy: Moral awareness and empathic concern as moderators. Applied Psychology 62(2):211-235. (DOI:http://dx.doi.org/10.1111/j.1464-0597.2011.00483.x.)

KANGAS M, FELDT T, HUHTALA M \& RANTANEN J. 2014. The corporate ethical virtue scale: Factorial invariance across organisational samples. Journal of Business Ethics 12(1):161-171. (DOI:10.1007/s10551-0131851-7.)

KAPTEIN M. 2008. Developing and testing a measure for the ethical culture of organizations: The Corporate Ethical Virtues Model. Journal of Organisational Behaviour 29(7):923-947. (DOI:10.1002/job.520.)

LOCKE EA. 1976. The nature and causes of job satisfaction. Handbook of Industrial and Organizational Psychology 1:1297-1343.

MAYER DM. 2014. A review of the literature on ethical climate and culture. In The handbook of organizational climate and culture: antecedents, consequences, and practice. Eds. Schneider B \& Barbera K. New York, NY: Oxford University Press. (pp 415-440.)

MITONGA-MONGA J. 2018. Employees' work engagement in a railway organisation: A perspective of ethical work climate and leadership behaviour'. Acta Commercii 18(1):a598. [Internet:https://doi.org/10.4102/ac.v18i1.598; downloaded on 19 February 2019.] 
MITONGA-MONGA J \& CILLIERS F. 2015. Ethics culture and ethics climate in relation to employee engagement in a developing country setting. Journal of Psychology in Africa 25(3):242-249. (DOI:10.1080/14330237.2015.1065059.)

MITONGA-MONGA J \& CILLIERS F. 2016. Perceived ethical leadership: Its moderating influence on employees' organisational commitment and organisational citizenship behaviours. Journal of Psychology in Africa 26(1):35-42. (DOI:10.1080/14330237.2015.1124608.)

MITONGA-MONGA J, FLOTMAN AP \& CILLIERS F. 2016. Workplace ethics culture and work engagement: The mediating effect of ethical leadership in a developing world context. Journal of Psychology in Africa 26(4):326-333. [Internet:http://dx.doi.org/10.1080/14330237.2016.1208928; downloaded on 18 March 2019.]

MULLINS L. 2013. Management and organizational behavior. 10th Ed. London: Pearson.

MUSTAFA G, IIYAS M \& REHMAN A. 2016. Do the employees' job satisfaction interferes organizational culture and affective commitment relationship: Test of Bootstrap Meditation. Journal of Applied Environmental Biological Science 6(5):125-133.

SALEM I. 2015. Transformational leadership: Relationship to job stress and job burnout in five-star hotels. Tourism and Hospitality Research 15(4):240-253. [Internet:https://doi.org/10.1177/1467358415581445; downloaded on 06 March 2019.]

SCHWEPKER CH. 2001. Ethical climate's relationship to job satisfaction, organizational commitment, and turnover intention in the salesforce. Journal of Business Research 54(1):39-52. (DOI:http://dx.doi.org/10.1016/S0148-2963(00)00125-9.)

SEHUNOE N, VIVIERS R \& MAYER CH. 2015. Job satisfaction, organisational commitment and work engagement in an insurance company. South African Journal of Labour Relations 39(2):123-144.

STRAND VC \& DORE M. 2009. Job satisfaction in a stable state child welfare workforce: Implications for staff retention. Children and Youth Services Review 31:391-397. [Internet:http://dx.doi.org/10.1016/j.childyouth.2008.09.002; downloaded on 28 November 2018.]

STRÜMPFER DJW \& DE BRUIN GP. 2009. Antonovsky's sense of coherence and job satisfaction: Metaanalysis of South African data. South African Journal of Industrial Psychology 35(1):1-3. (DOI:10.4102/sajip.v35i1.767.)

TABACHNICK BG \& FIDELL LS. 2013. Using multivariate statistics. $6^{\text {th }}$ ed. Boston: MA: Pearson.

TRANSPARENCY INTERNATIONAL. 2018. Corruption is threatening prosperity for all. [Internet:https://www.transparency.org/cpi; downloaded on 14 May 2019.]

TREVIÑO LK. 2010. (Un)Ethical Behavior in Organizations. Annual Review of Psychology 65(1):635-660.

TREVIÑO LK, BUTTERFIELD KD \& MCCABE DL. 1998. The ethical context in organisations: Influences on employee attitudes and behaviours. Business Ethics Quarterly 8(1):447-476.

TREVIÑO LK \& NELSON KA. 2010. Managing business ethics. $5^{\text {th }}$ ed. London: John Wiley \& Sons.

TSAI Y. 2011. Relationship between organisational culture, Leadership Behaviour and Job satisfaction. BMC Health Services Research 11:1-9.

TU Y, LU X \& YU Y. 2017. Supervisors' ethical leadership and employee job satisfaction: A social cognitive perspective. Journal of Happiness Studies 18:229-245. (DOl:http://dx.doi.org/10.1007/s10902-016-9725-1.)

VALENTINE S, GRELLER MM \& RICHTERMEYER SB. 2006. Employee job response as a function of ethical context and perceived organisational support. Journal of Business Research 59(5):582-588. (DOl:http://dx.doi.org/10.1016/j.jbusres.2005.06.004.)

VITELL SJ \& DAVIS DL. 1990. The relationship between ethics and job satisfaction: An empirical investigation. Journal of Business Ethics 9(6):489-494. (DOI:10.1007/BF00382842.)

VROOM VH. 1964. Work and motivation. New York: Wiley. 
WALUMBWA FO, AVOLIO BJ, GARDNER WL, WERNSING TS \& PETERSON SJ. 2008. Authentic Leadership: Development and Validation of a Theory Based Measure. Journal of Management 34:89-126. (DOI:10.1177/0149206307308913.)

WONG KK. 2011. Review of the book Handbook of Partial Least Squares: Concepts, Methods and Applications. In Esposito V, Chin WW, Henseler J \& Wang H. Eds. International Journal of Business Science \& Applied Management 6(2):52-54.

YANG C. 2014. Does ethical leadership lead to happy workers? A study on the impact of ethical leadership, subjective well-being, and life happiness in the Chinese culture. Journal of Business Ethics 123(3):513-525. (DOI:10.1007/s10551-013-1852-6.) 